\title{
Comprehensive Drafts of Woven Fabrics
}

\author{
Oghale Omojuwouvie Okpu¹, Ojeo Oluwafunmilayo Loromeke ${ }^{2}$ \\ ${ }^{1}$ Department of Fine and Applied Arts, Delta State University, Abraka, Nigeria \\ ${ }^{2}$ Department of Fine and Applied Arts, Ambrose Alli University, Ekpoma, Edo State, Nigeria \\ Email: Ookpu@yahoo.com, Oluloromeke@yahoo.com
}

How to cite this paper: Okpu, O.O. and Loromeke, O.O. (2020) Comprehensive Drafts of Woven Fabrics. Journal of Textile Science and Technology, 6, 130-143.

https://doi.org/10.4236/jtst.2020.63011

Received: June 29, 2020

Accepted: August 8, 2020

Published: August 11, 2020

Copyright $\odot 2020$ by author(s) and Scientific Research Publishing Inc. This work is licensed under the Creative Commons Attribution International License (CC BY 4.0).

http://creativecommons.org/licenses/by/4.0/

\begin{abstract}
The crux of this paper is based on the pattern drafting of woven fabrics. It is necessary because many textile designers or weavers cannot generate and develop their personal pattern drafts for weaving. It is obvious that they mainly copy other people's designs to weave. This paper therefore has provided an easy and simple way to learn, focus and develop their original designs to weave. The practical production method is used to create, generate and develop the pattern drafts in this paper. The paper focuses on the components of the pattern draft which will surely help to forecast and have a view of the appearance of the design before it is woven on the cloth. In conclusion, the weaver will be able to record and document his/her original works for posterity.
\end{abstract}

\section{Keywords}

Pattern Draft, Basic Unit, Lifting Plan, Threading and Treadling Drafts

\section{Introduction}

This paper examines the technicalities involved in the drafting of patterns for different structural designs of woven fabrics. It also discusses the factors necessary for the building plan, the interpretation of the notation used to the understanding of the weaver or textile designer. It also states the usefulness of these symbols to the textile designer or weavers because most of them cannot decipher the signs or symbols used for the draft (building plan) of woven fabrics.

Information is gathered from literary source, such as art journals, books and the internet. The practical production technique is used to create, generate and concretize the building plans by the use of the weaving formula associated with the drafts. The factors or the components of the comprehensive pattern draft on point paper are discussed and illustrated as necessary. 
This paper tries to simplify the pattern drafts as building plan of woven designs, to alleviate the fears of most textile designers, who are not conversant with the rules and regulations guiding the pattern drafting of woven fabrics. The draft enables the weaver to forecast or have a fair knowledge of the fabric to be produced as it involves accurate pattern on point paper. The pattern draft also helps the weaver to have deep understanding of the weaving process and eventually enables him/her to produce original designs. With this procedure, the weaver will keep a record of all his/her works. It has been observed that a careful study of pattern drafting enables the weaver to understand and develop new original designs for different productions thereby making analysis of weave structures very easy and possible.

This paper is hinged on Roland Barthes Semiotic theory in his book based on mythologies of 1957. Barthes's ideology of signs ranging from speech, body language and symbols in paintings, music and Morse code was discussed by [1]. Hall further stated that Barthes's semiotic theory broke down the process of reading signs and focused on their interpretation by different cultures and societies. According to Barthes, signs had both a signifier being the physical form of a sign as we perceive it through our senses or the signified or meaning that is interpreted. He also believed that every ideological sign is either a denotative sign system or a connotative sign. This is what the graphical notations of drafting plan in weaving are built upon. Only those who can understand and interpret the signs would be able to lay the foundation of the pattern drafting on the loom and weave the structural design as the woven fabric is formulated or fabricated.

\section{Pattern Drafting}

Pattern drafting is a set of mark or characters used to designate the order in which the threads are drawn into the heddle to form the weave according to [2]. She also observed that there are a lot of variations in the recording of these patterns drafting. This depends on the various weavers in different countries, as well as different parts of the same country and at different periods devised their own methods of draft writing. Some resemble short hand in their brevity while others are long.

Brown opined that amateur weaver is always confronted with mysterious diagrams marked up with blackening squares, or Xs or Os or numbers which are regarded as patterns drafts. These drafts represent a code by which the weaver can thread the heddles of a multi-harness loom so that certain sequences of threads can be raised or lowered [3]. It automatically means that two shaft loom cannot produce structural weaves because we do not need the code, as threading the warp is alternately through heddles on the first and second harnesses. However, for the so-called structural weaves where sometimes very complicated sequences of threads are raised and lowered, the weaver needs a kind of simplified guidance and direction for threading the heddles and this is where the draft is indispensable. Hence, it is very necessary for a weaver to understand the basic principles of drafting which is a formula [4]. 
Although pattern drafting is regarded as a system of notation used to represent graphically the appearance and mechanics of a weave, it is advisable for a weaver to be able to decode and understand the signs embedded in the drafting [5]. She further stated that drafting system is a very serious and tedious exercise if a weaver wants to be creative and innovative. Elnashar also stated that it is very possible to use Beethoven music harmony with matrix drafting concept for creating and developing interesting, complex and rhythmic patterns [6]. It means that without the knowledge of music and its notations, the individual cannot understand the drafting system.

It is also suggested that colors can be used to create drafting patterns on fabrics demonstrated on automatic Jacquard Looms, so it is necessary to have technical knowledge and skill of transferring a pattern on a fabric [7]. Pattern drafting in weaving can also be used for garment patterns directly on electronic Jacquard Looms with the Bonas software by digitalizing the patterns [8].

According to Bird "pattern drafts" are usually plotted on graph paper, so that one may see the design as it would appear on the face of the fabric [9]. In the book "sample weaving", stated that drafting on graph paper is an important method of bridging the gap between the original design idea and the actual fabric [10]. He believes it is quite frustrating when a weaver is unable to try an idea because he/she does not know how to thread the pattern on the loom. This is the aspect the researchers called "laying of the foundation" or "dressing the loom" for the pattern drafting to be woven into fabric.

\section{Discussion and Analysis}

\subsection{Point Paper (Design Paper)}

It is like a general graph paper that is used for mathematical calculation. It is ruled with vertical and horizontal lines in a manner suitable for showing weaves and designs. Generally each space between vertical lines represents one warp yarn or end while the horizontal spaces/lines indicate the weft yarn or pick. It should be noted that the point paper/design paper is the main material for creating, generating and developing pattern drafting. Other accessories are pen, pencil, ruler and eraser which are used to draw, develop, arrange, and organize the signs of the draft according to the design formulation. Figure 1 shows the sample of point/design paper. This size of the squares used for the draft paper is $1 / 2 \mathrm{~cm}$ each. Some designers use $1 \mathrm{~cm}$ each square, others may use bigger squares during the learning process. However, it depends on the designer or weaver to use the sizes suitable for the process. Finally, we used computational tools to construct all the images on the graph papers to improve our understanding of the harnesses and the modern technology of pattern drafting.

\subsection{The Principles or Factors Responsible for Pattern Drafting}

Building plan of any house depends on the type of building which may be for a commercial, residential, recreational parks and markets. All these differ in their 


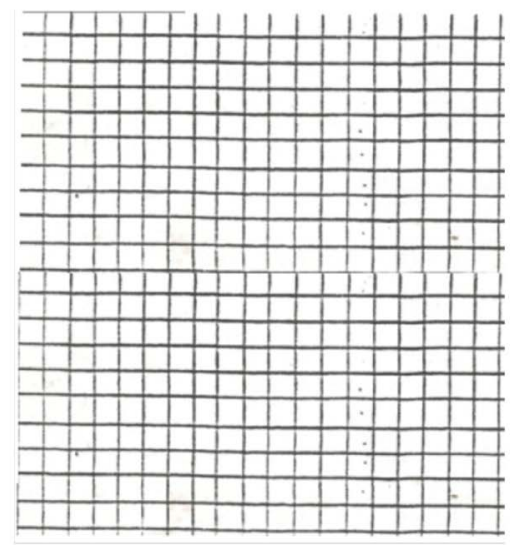

Sample of Design / Graph Paper

Figure 1. Point paper.

architectural planning. This also applies to the building planning of woven fabrics for dress wears, furniture and office wears. This also depends on the type of loom used for the formulation.

The pattern draft of this paper is directed to the manual four (4) shaft floor loom which is manipulated by the hands at the top and the leg on the pedals at the bottom. So the bottom shedding technique is being used for this type of loom.

The following are the main factors or components of a detailed comprehensive pattern draft on a point paper. The Components of patterns drafting can also be created, generated and developed with the aid of a software program for drafting patterns in computer. It is not easily available hence the use of computational tools for the drafting on point paper.

1) Basic unit

2) Unit pattern

3) Weave plan/Design

4) Draft (threading draft)

5) Lifting plan, peg plan, tie-up

6) Pedals (draft)

7) Treading draft

8) Sectional diagrams

8a) Warp

8b) Weft

Before the weaver starts drafting he/she should adhere to the manner of selection. Even number should not follow even number, and odd number should not follow odd number in the selection of the numbers from 1, 2, 3 and 4 of each warp yarn to be threaded. This rule must be observed for a successful creation, manipulation and designing of the pattern draft.

Now, just visualize the top of a four shaft floor loom, you will be looking at the four harnesses as it will appear as in Figure 2. Figure 2: Represents a visual appearance of the harnesses of a 4 shaft loom when the individual is standing physically at the front, looking at the loom. The length of the shaft/harness is 


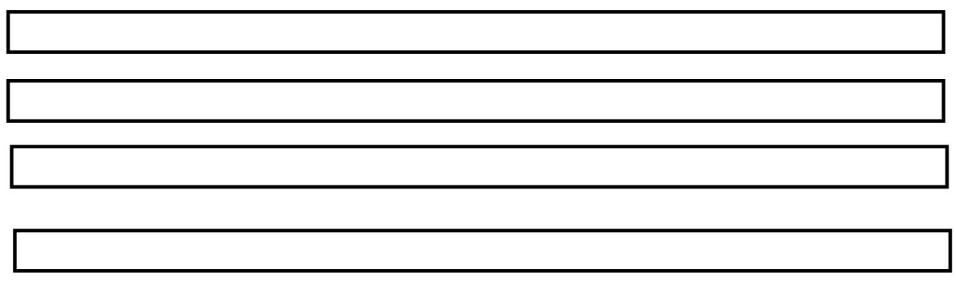

Figure 2. Visual appearance of the harnesses of a 4 shaft loom.

about $75 \mathrm{~cm}$ long. But we used $7 \mathrm{~cm}$ to represent the length where the heddles are normally inserted.

The four harnesses are drawn on a point paper/graph paper. Every square ( $1 / 2$ $\mathrm{cm}$ in size) represents a space where a single heddle could be threaded as in Figure 3.

\section{Interpretation and Results}

\subsection{Basic Unit}

This is the first unit of the pattern created, which is repeated to formulate the unit pattern. It shows how the arrangements of the picks (weft yarns) are woven on top of the warp yarns on the four shafts/harnesses. This is shown in Figure 4. The dark areas show where the warp yarns are over the weft yarns, while the white areas represent the weft yarns are over the warp yarns. The Alphabet $P$, represents the movement of the shuttle (carrying the weft yarns) from one side of the loom to the opposite side. The weft thread is beaten down with the reed. The shed is opened again for the shuttle, P2 (carrying the weft yarn) to pass through, then the P3 and P4 continuously until the formation is completed.

\subsection{Unit Pattern}

This is the translation and development of the Basic Unit to the Unit pattern in a repeated form, to generate the design. Let us take the formation of a pattern of the following numbers, making sure that odd number do not follow odd number and even number do not follow even number such as 12343234, 12343234. This means that the design repeats in every eight warp end as shown in the unit pattern Figure 5.

Figure 5: Each square is $1 / 2 \mathrm{~cm}$ and the design repeats are in every eight yarn which means, the unit pattern has 16 squares vertically and 4 squares horizontally. Then use the numbers $1,2,3,4$ on the vertical squares of the basic unit to plot the graphical notation. Take each number, e.g. 1 and trace it vertically to plot the dark spaces. The same goes for numbers 2, 3 and 4 , continue in this manner until the sixteen spaces are exhausted with the numbers chosen.

\subsection{Weave Plan}

This is the visual appearance of the pattern created and it is the representation of the order of interlacing of the ends and picks. Each small square on the design/point paper represents a point of interlacing. When the warp is over 




Figure 3. Blank draft for a four harness weave.

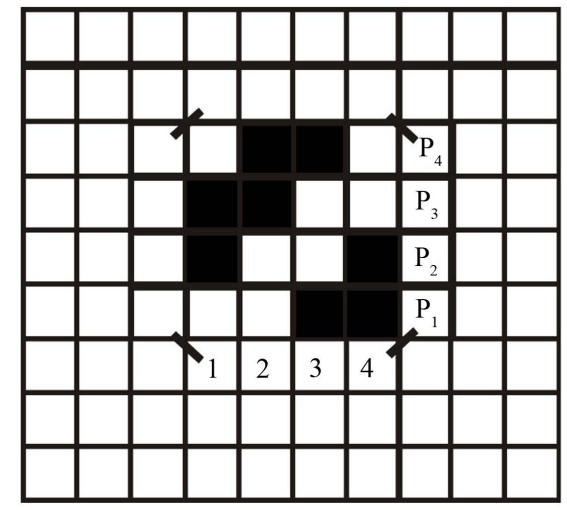

Figure 4. Basic unit of bottom shed.



Figure 5. Unit pattern: A repeat of the design on eight ends.

(above) the weft, the small square in the design paper is painted black. When the weft is over the warp, the small square in the design paper is left blank as determined by the design pattern in Figure 5(a). This pattern will show exactly on the woven fabric as designed. The warp draft and the weft draft are the same in numbering such as 12343234 . This is repeated according to the width and length of fabric desired. Figure 6(a) is the weave plan used for the first pattern drafting. 


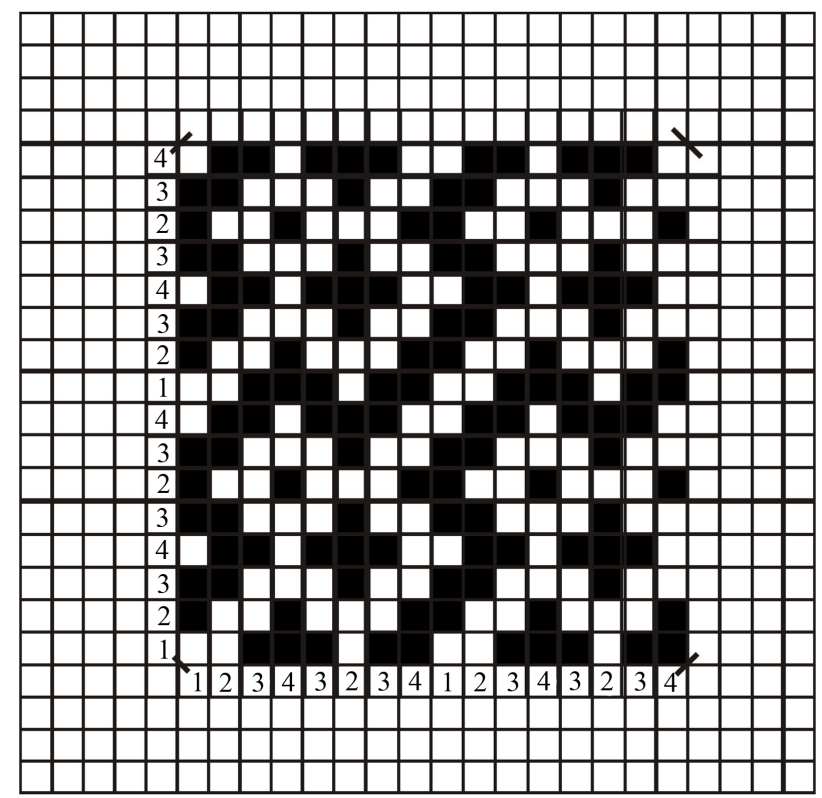

(a)

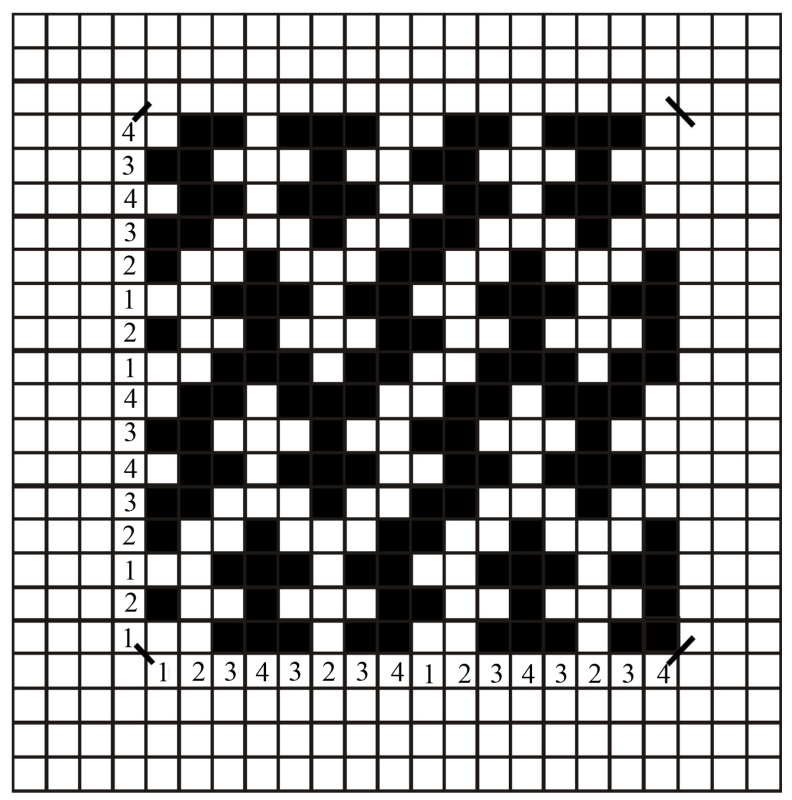

(c)

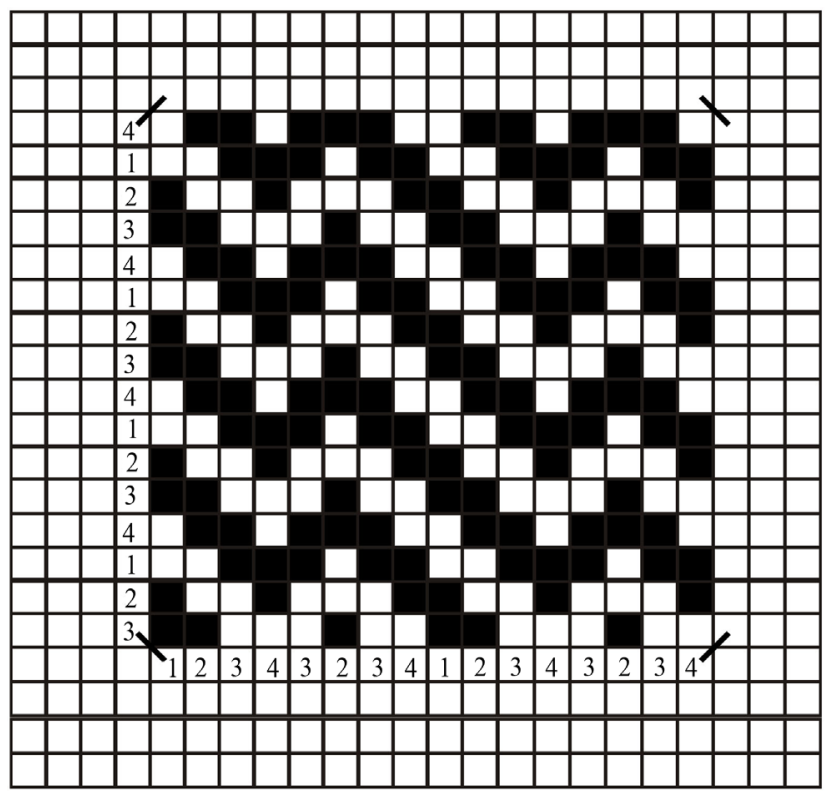

(b)

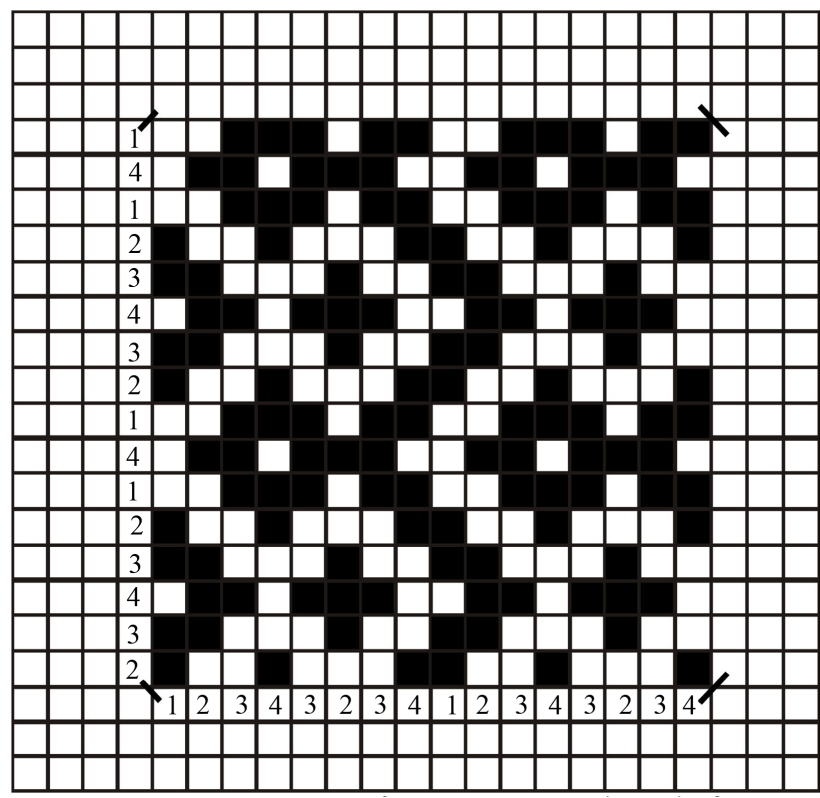

(d)

Figure 6. (a) Weave plan; (b) Weave plan (variation on weft draft 1); (c) Weave plan (variation on weft draft 2); (d) Weave plan (variation on weft draft 3 ).

This plan is formulated on $8 \mathrm{~cm}$ by $8 \mathrm{~cm}$ dimension in $1 / 2 \mathrm{~cm}$ square spaces. The numbering of 1234323412343234 are positioned on each square vertically and horizontally. The plotting and arrangement of the dark areas starts from number one: 1) on the horizontal line to shade the dark areas to the end from the unit pattern. Then start with number two: 2) on the horizontal line and shade the dark areas along the line to the end. The same applies to number 3, 4 and others accordingly, until the design is completed. The development of the design comes up as you plot the graph. Until the full plotting is done, one cannot easily deter- 
mine the weave structure.

Figure 6(b) also represents the same weave plan of $6 a$ of the warp draft of 12343234 , but the weft draft is 32143214 , hence the variation of the original pattern draft. The variation of any original weave is determined by the weft draft. In this design, the researchers decided to change the numbers of the weft draft to 3214321432143214. Plotting the graph from the unit pattern as in Figure 6(a), shows that the numbering on the horizontal lines has changed, hence the variation. One can see that the drafting started with numbers 3214-and ended with 3214 which is at variance with that of Figure 6(a).

We tried with another sample with the numbers 1212343412123434 for the weft draft. After plotting the graph, using the unit pattern, the result is the pattern draft in Figure 6(c) giving a different movement, rhythm and harmony of the dark images formed. It is still derived from the warp draft of Figure 6(a).

This variation was created and developed using different numbers of 2343214123432141 for the weft draft and the resultant is the graphical draft pattern is the graphical draft pattern on Figure $6(\mathrm{~d})$. The use of the unit pattern is a must to arrive at your draft. The most interesting aspect of this technique of creating and generating pattern draft, is the originality, uniqueness and dynamism experienced in this method. The structural movements of the images are well spread and positioned in strategic areas of the design.

\subsection{The Threading or Drawing-In Plan (Draft)}

This is the graphical representation of the order in which the warp yarns are threaded through the eyes of the heddles. This is referred to as a draw or a draft. Below is a straight draft notation on a four-harness loom showing a threading arrangement based on a unit of 4 warps repeated across the loom as shown in Figure 7.

When sitting on the loom, the first shaft or harness facing the weaver is regarded as shaft 1 , next is 2 , the next is 3 and so forth with their respective heddles. According to the draft in Figure 7:

Warp 1 is threaded through harness 1

Warp 2 is threaded through harness 2

Warp 3 is threaded through harness 3

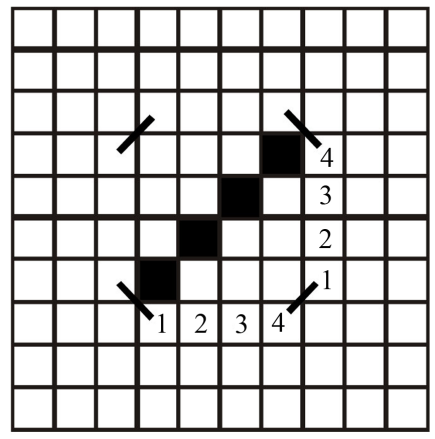

Figure 7. Straight draft. 
And warp 4 is threaded through harness 4 and once one unit or repeat has been completed, the pattern begins again. The draft is normally read from the bottom to top as the harnesses occur from the front to the back of the loom.

The draft for the weave plan of $6 \mathrm{a}, 6 \mathrm{~b}, 6 \mathrm{c}$ and $6 \mathrm{~d}$ will be created according to numbers forming the unit which is12343234. This is threaded for the draft to be repeated as shown in Figure 8.

\subsection{The Lifting Plan/Peg Plan/Tie-Up}

The lifting plan defines the selection of heddles to be lifted or lowered on each successive insertion of weft yarn. In a lifting plan, the vertical spaces represent the heald or heddle shafts and the horizontal spaces indicate the picks (weft). The lifting is derived from the weave plan of any pattern. The lifting plan (Figure 9) is derived from the weave plan (Figure 6(a)). The horizontal squares or spaces painted represent where the warp yarn is over the weft yarn during weaving. Where the weft yarn is over the warp yarn, it is left blank. The graphical notation is formulated from the first four vertical squares of the weave plan with the numbers 1234 . The graph plotting is taken vertically by shading the dark areas along the squares till the end of the design. From the analysis above, one can deduce that the lifting plans of $6 \mathrm{~b}, 6 \mathrm{c}$ and $6 \mathrm{~d}$ must vary because of the differences in their weft drafts.

\subsection{Pedals/Treading (Draft)}

This is the tying of the ropes/twines from the shafts to the lams, down to the treadles. In fact this is the final factor to be considered as it is the order of pressing the treadles to create their respective sheds as shown on the pedal or Treadling Draft as shown in Figure 10.

From Figure 10, the horizontal squares, shaded and unshaded represent the shafts while the vertical squares, shaded and unshaded represent the treadles or pedals. It shows that when Treadle one, represented by $\mathrm{T} 1$ is pressed down, shafts 1 and 2 (represented by Sh1 \& Sh2) will be lowered.

So Treadle 1 will lower shafts $1 \& 2$

Treadle 2 will lower shafts $2 \& 3$

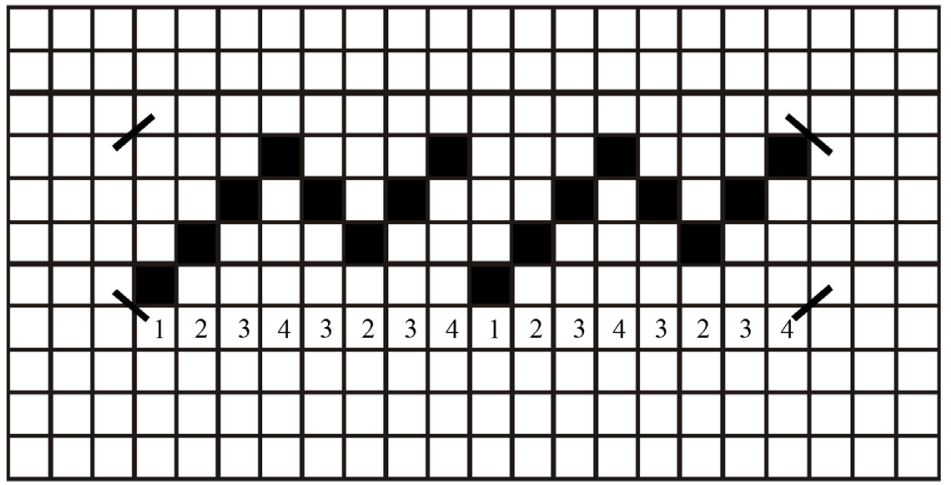

Figure 8. A threading draft for weave plan $6 a, 6 b, 5 c$ and $6 \mathrm{~d}$. 


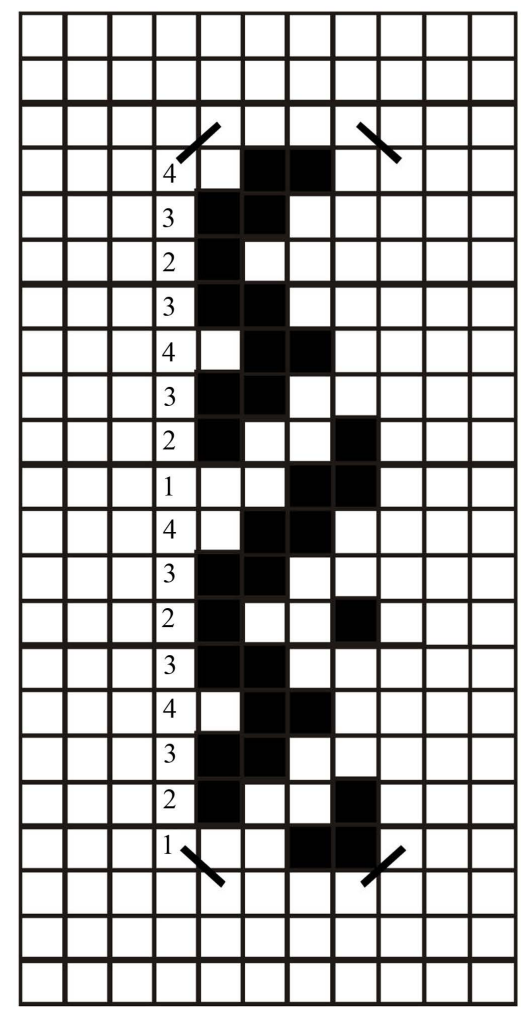

Figure 9. Lifting plan for weave plan 6a.

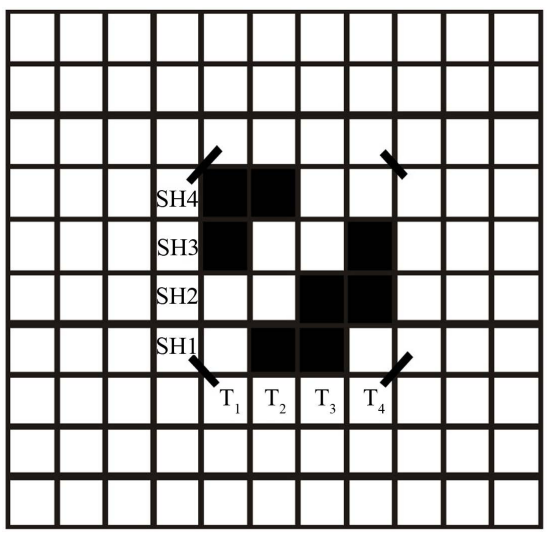

Figure 10. Treadling draft for 6 a.

Treadle 3 will lower shafts $3 \& 4$

Treadle 4 will lower shafts $1 \& 4$

Normally plain weave is used as the binding force to make the structural weave more taut, strong and firm.

Therefore Treadle 5 will lower shafts $1 \& 3$ and

Treadle 6 will lower shafts $2 \& 4$

\subsection{Treadling Order}

The treadling order indicates the order of lifting the shafts in a peculiar manner to show the structural weave as it appears on the surface of the woven cloth. For 
example in Figure 6(a) lifting plan, the first (1) weft yarn that is passed through shaft 1 , is represented with a slash sign. The slashes are arranged according to the number of times the treadles are lowered to execute the drafted design. Therefore the treadling order should correspond with the lifting plan numbering on the right hand side by the weave plan. The treadling order is in Figure 11 and the fixture of the slashing is according to the pattern draft.

\subsection{Sectional Diagrams}

The first movement of the weft thread on the front of the loom represents the sectional diagram for the weft. When one stands at the side of the loom, the first warp thread vertically placed represents the sectional diagram for the warp.

\subsection{The Comprehensive Draft Pattern}

This is a conglomeration of all the factors or components of pattern drafting as seen in Figure 12. At a glance you can see and meditate on how the pattern draft is created, generated and developed into a complete woven structure. The mental thinking or concept started with the standard formula of the Basic unit of a bottom shedding loom. The formation of the unit pattern is the repeat of the basic unit numbers. The weave plan is generated from the unit pattern by plotting the dark areas of numbers 1234 horizontally till the end of the Sixteenth Square. The

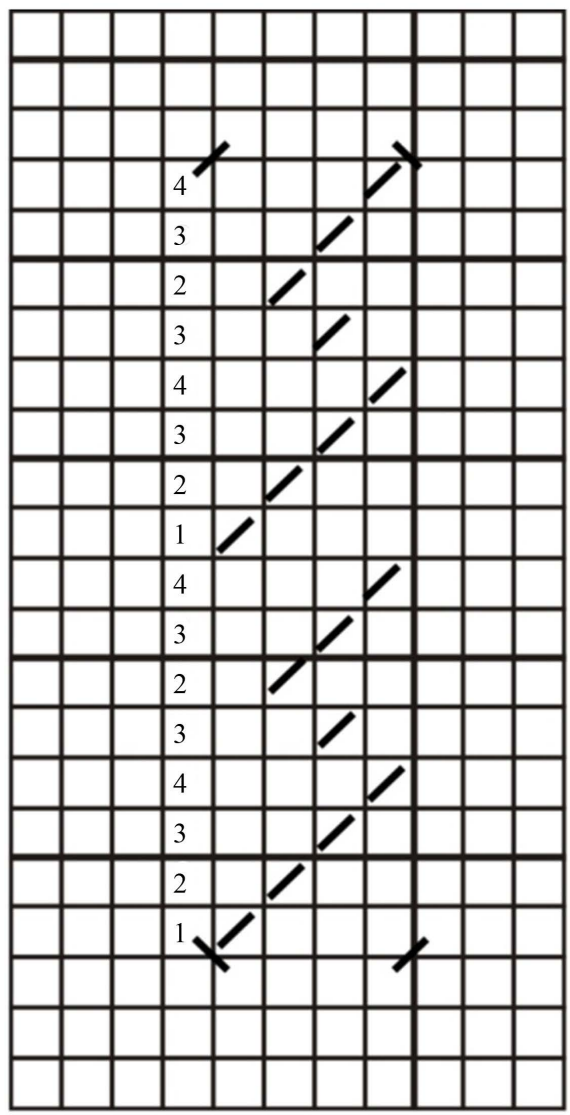

Figure 11. Treadling order for $6 a$. 
COMPREHENSIVE DRAFT PATTERN

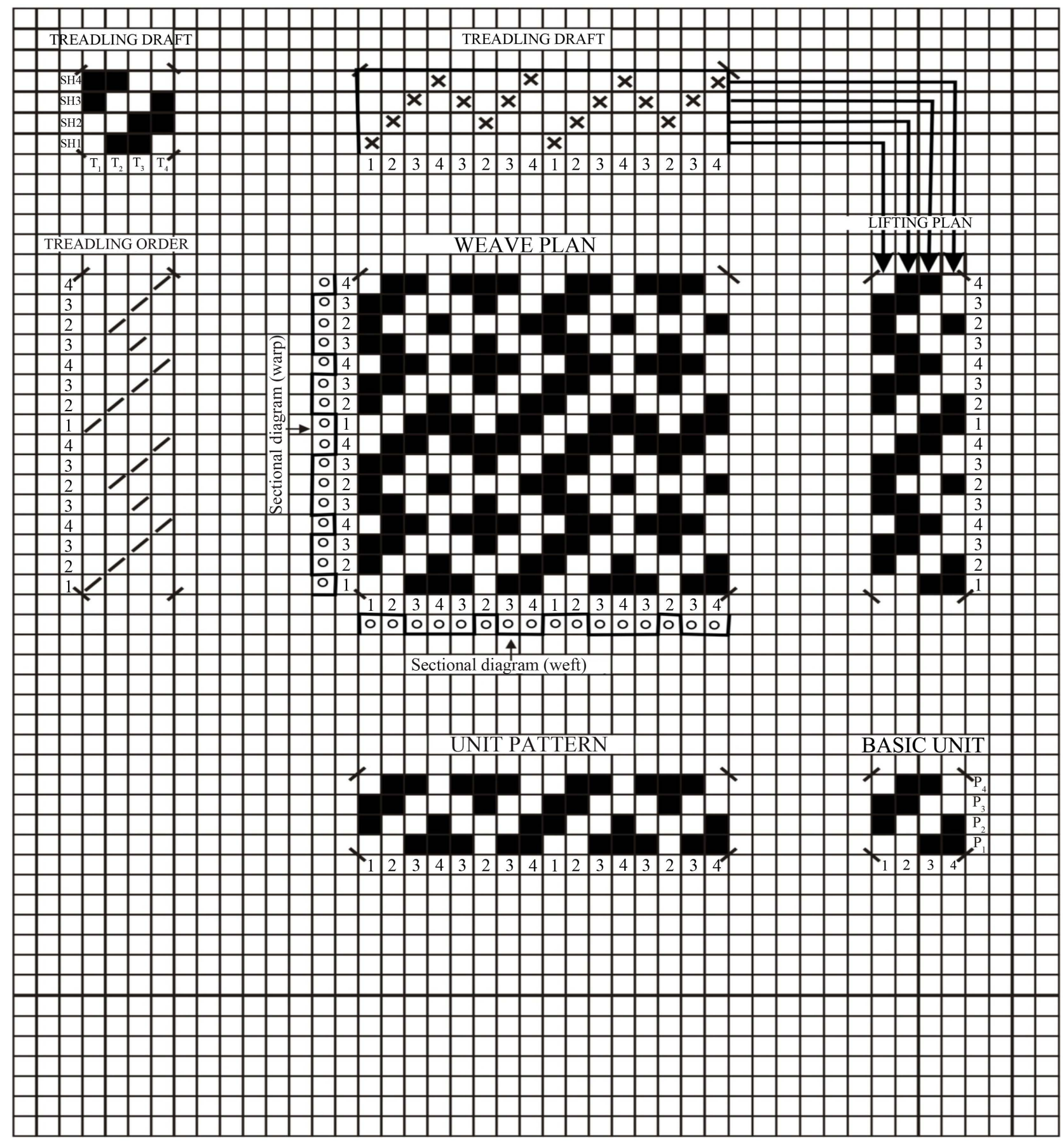

Figure 12. The comprehensive draft pattern.

pattern continues until the end of the design. The next stage which is the lifting plan is derived from the first four squares numbered 1234 vertically on the weave plan. The threading plan represents how the warp yarns are passed through the heddle's eye on the shafts or harnesses. The lines from the threading plan to the lifting plan show how the movements of the shafts are lifted up and down when the pedals are pressed down. At the extreme left hand side of the 
comprehensive draft is the treadling order, which shows the number of times each number is lifted when a treadle is lowered. From the above statement, it is obvious that some numbers are more frequently lifted than others because of the design.

\section{Conclusions}

The paper has discussed extensively on the components or factors used for pattern drafting. It has successfully simplified the whole process by explaining all the factors necessary for pattern drafting one after the other for easy understanding. This is to encourage any textile designer or weaver willing to create, generate, develop and analyze his/her pattern drafts. Continuous practicing of these graphical notations will make the individual develop and record all his/her original pattern draft for posterity. All these pattern drafts are used mainly by the multi-harness looms which are very efficient in terms of production and fastness as projected by [11].

Some of the advantages of this method are: the draft patterns can be sold to weavers and entrepreneurs who cannot draft their designs, it gives self-satisfaction as the result is beautiful, and worthy to appreciate, it is a simple technique and straight foreword to understand pattern drafting, it is a draft pattern made easy and it gives the designer the zeal to draft more. It is less time consuming once the knowledge is known and mastered.

From all indications, pattern drafting is an interesting, creative and innovative experience worth knowing. It is a process of mental tasking that no TOM, DICK and HARRY can handle. It is mainly for practicing professional or weavers that are skillful [12]. Anybody who is willing to learn, create and develop the threading draft using the standard Basic Unit of Bottom shed can excel very well after many attempts of pattern drafting. It has been observed that from the creation and development of these pattern drafts, a lot of academic revelations have occurred, such as original and unique pattern drafts peculiar to the designer. Each result gives the designer the zeal to work more. It is very tasking and makes the individual meditate more. It is an area in textile that designers can develop their drafts to sell to weavers who cannot create their own draft patterns. It is a good entrepreneurial skill that can move business in the textile market, if well directed. The researchers also discovered that the more numbers used as a unit pattern to create a repeat, the more complex, intricate and diversifying design. Although it is time consuming and stressful, the resultant of the draft is more complex, enticing and aesthetically appealing. However, the drafting of patterns for structural weaves in textile gives one satisfaction and complimentary mental coolness. It is obvious that the process of designing leads to innovative products which require skillful knowledge [13]. It is observed that weavers have continued to strive to improve and make new surface qualities [14]. Pattern drafting is a good entrepreneurial skill that can move business in the textile market, if well-orchestrated. 


\section{Acknowledgements}

The writers of this paper acknowledged all our colleagues that contributed in one way or the other to make sure that this write-up is successful, especially in the area of the interpretation of the pattern drafts. We are also very grateful to our families for their support financially, morally and prayerfully.

\section{Conflicts of Interest}

The authors declare no conflicts of interest regarding the publication of this paper.

\section{References}

[1] Hall, S. (2016) Roland Barthes and His Semiotic Theory. UK Essays in Cultural Studies. Goldsmiths, University of London, London.

[2] Black, M.E. (1980) Key to Weaving: A Textbook of Hand Weaving for the Beginning Weaver. Macmillan Publishing Co. Inc., New York.

[3] Brown, R. (1979) The Weaving, Spinning and Dyeing Book. Routledye \& Kegan Paul Ltd., London and Henley.

[4] Chetwynd, H. (1977) Weaving in Easy Steps. A Studio Vista Book. Cassell \& Collier Macmillan Publishes Ltd., New York.

[5] Okpu, O. (2014) “The Introduction” Exploring Four-Shaft Loom for Production of Structural Drafts for Weaving Fabrics. Ph.D. Exhibition Catelogue, Ajiginni Margaret Irobunor Delta State University, Abraka.

[6] Elnashar, E.A. (2020) Beethoven Music Harmony in Design Weaving Fabric between Harness and Matrix Drafting Theories. International Journal of Applied Science and Research, 3, 21.

[7] Kovacevic, S. and Schwaiz, L. (2015) Weaving Complex Patterns-From Weaving Looms to Weaving Machines. Cutting Edge Research in Technologies INTECH. https://doi.org/10.5772/61091

[8] Ukey, P., Kadole, P.V. and Borikar, S. (2013) Direct Pattern on Loom-An Innovative Method of Garment Construction. Journal of Textile Science \& Engineering, 3, 2. https://doi.org/10.4172/2165-8064.1000131

[9] Bird, J. (1997) Creative Projects for the Home Country Fabric Style. Trafargar Squares Publishing, USA.

[10] Chetwynd, H. (1969) Sample Weaving. A Studies Vista. Cassell \& Collier Macmillan Publishers Ltd., New York.

[11] Asiedu-Gyampoh, A. (1999) Contemporary Adaptation of the Nigerian Traditional Textile Industry in Delta State. First Rhythms 1999 Independence Art Exhibition. Society of Nigerian Artists, Delta State Chapter.

[12] Asiedu-Gyampoh, A. (2020) Textile Consultant. Personal Interview 15/5/2020.

[13] Seymor, R. (2002) What Is Design, Design Council's: Design in Business Week. https://www.designcouncil.org.uk/

[14] Nicole, R. (2011) Textile Design: Principles Advances and Application. Wood Head Publishing Ltd., Oxford. 